\title{
PROFISSIONALIZAÇÃO DOCENTE: CONEXÃO ENTRE TEORIA, PRÁTICAS EDUCATIVAS E TRABALHO COLETIVO EM UMA POLÍTICA PÚBLICA DE FORMAÇÃO
}

\author{
EV'ÂNGELA BATISTA RODRIGUES DE BARROS \\ Pontifícia Universidade Católica de Minas Gerais (PUCMINAS), Belo Horizonte, Minas \\ Gerais, Brasil \\ LORENE DOS SANTOS \\ Pontifícia Universidade Católica de Minas Gerais (PUCMINAS)/ Universidade do Estado de \\ Minas Gerais (UEMG), Belo Horizonte, Minas Gerais, Brasil
}

\begin{abstract}
Resumo: Este artigo discute a profissionalização docente enfocando algumas das tensões, disputas, avanços e recuos historicamente presentes na formação inicial de professores, a partir da apresentação e discussão de resultados de uma pesquisa qualitativa desenvolvida com 103 egressos do Programa Institucional de Bolsas de Iniciação à Docência (Pibid) de quatro universidades mineiras. Dialogando com depoimentos desses jovens professores, busca-se entender o papel e a atuação de diferentes sujeitos na formação inicial docente, perscrutando a importância do compartilhamento de saberes e experiências para o enfrentamento de alguns dos dilemas vivenciados em início da carreira de magistério. Os achados da pesquisa confirmam a importância de se investir em diálogos universidades-escolas de educação básica e a potencialidade de comunidades de aprendizagem e outros espaços de partilha de saberes para o enfrentamento de desafios e entraves históricos aos processos de formação docente.
\end{abstract}

Palavras-chave: Profissionalização Docente. Formação Inicial de Professores. Pibid. Comunidades de Aprendizagem.

\section{INTRODUÇÃO}

Este artigo discute a profissionalização docente, tendo como foco uma política pública de formação inicial de professores, empreendida na última década em nosso país: o Programa Institucional de Bolsas de Iniciação à Docência (Pibid). A primeira parte do artigo, de natureza mais ensaística, problematiza alguns dos dilemas e desafios que atravessam a formação inicial e a profissionalização docente, buscando elucidar processos que, historicamente, contribuem para perpetuar a desvalorização social da profissão, sua (crescente) baixa atratividade para as novas gerações e os altos índices de abandono nos primeiros anos de magistério. A segunda parte do artigo é dedicada à apresentação e discussão de resultados de uma pesquisa qualitativa, desenvolvida com 103 egressos das licenciaturas de quatro universidades mineiras, que participaram do 
Pibid durante sua formação inicial. Entre os vários aspectos que emergiram na pesquisa, desenvolvida por meio de um questionário eletrônico composto de questões fechadas e abertas, privilegiou-se, neste texto, a discussão sobre a potencialidade do trabalho coletivo e da constituição de "comunidades de aprendizagem" (conforme discutido por NÓVOA, 2017), buscando entender se - e de que maneiras - tais elementos contribuem para melhor qualificar a formação inicial docente e, assim, minimizar alguns dos obstáculos e dificuldades vivenciados no início de carreira, o que leva muitos jovens professores a desistirem do magistério nos primeiros anos de inserção profissional.

$\mathrm{O}$ esforço por entender a profissionalização docente no Brasil demanda um olhar para um processo que se acentua no decurso do século $X X$, mas que tem raízes históricas bem mais remotas. Também pressupõe lançar um olhar mais alargado, que evidencia semelhanças com os demais países da América Latina, em cujo percurso pesa a dependência financeira e, portanto, a sujeição a orientações e injunções de organismos internacionais (OLIVEIRA, 2011; MARTINS, 2013).

Observa-se uma crescente rejeição das licenciaturas pelos jovens, que se soma ao abandono da carreira por muitos profissionais já inseridos no mercado de trabalho. A compreensão de tal situação requer análises que considerem a complexidade das relações interpessoais travadas na ambiência escolar, a tendência à redução da autonomia e um conjunto de novas demandas ao trabalho docente, que se acrescem às demais, igualmente desafiantes do processo de ensino, gerando uma exacerbação de cobranças e adoecimento de grande número de professores. A esse respeito, Oliveira (2011) reitera a análise de Fanfani (2005):

No Brasil, a profissão docente apresenta baixa atratividade em razão dos níveis de remuneração, das condições de trabalho e das expectativas oferecidas pelas carreiras. Como observa Tenti Fanfani (2005), as últimas décadas trouxeram nova realidade para o trabalho docente na América Latina, após duas décadas de constantes reformas na educação. Dentre elas, destacam-se: a ampliação quantitativa da profissão docente; a crescente heterogeneidade do trabalho docente; os crescentes graus de desigualdade entre os docentes; a deterioração das recompensas materiais e simbólicas; e crescentes consequências no plano subjetivo. (OLIVEIRA, 2011, p. 26).

A escolha de uma carreira por parte de jovens é algo bastante complexo. Muitas vezes, as escolhas são influenciadas por parentes que atuam em determinada profissão, pelo status ou imagem de glamour, às vezes pelo fascínio despertado por um professor dedicado à pesquisa, com uma aura de alguém que paira sobre os problemas mundanos.

No caso da escolha pela profissão docente, há que se considerar o fato de que todos os indivíduos que vivem nas sociedades contemporâneas, letradas e altamente escolarizadas, têm um contato próximo e cotidiano com profissionais do ensino desde a mais tenra idade, com possibilidades de serem influenciados por alguns desses inúmeros professores ao se defrontarem com o momento de sua escolha profissional. 
Por outro lado, esse longo contato com a escola e com uma sociedade letrada também permite que os jovens possam vivenciar, de perto, inúmeras situações que expõem, muitas vezes de forma ostensiva e flagrante, a desvalorização social da profissão docente, acentuada a partir das últimas décadas do século passado. É certo que as profissões são (des)valorizadas em consonância com mudanças sociais que, numa espécie de roda-gigante, iluminam certas carreiras (o que implica maior reconhecimento social e recompensas objetivas e subjetivas, nos termos de Oliveira, 2011) e obscurecem o valor e a relevância de outras.

Em relação a esse cenário, que faz os jovens preterirem um curso ou formação em prol de outro(a), e, igualmente, uma vez formados, a visarem uma área de trabalho e de pesquisa acadêmica em detrimento de outra, Angermuller e Hamann (2019, p. 82) afirmam que se instaura uma espécie de "lógica da celebridade", que exerce significativa força (centrípeta ou centrífuga):

Escolhas de carreiras e interesses de pesquisa são estruturados por aquelas tectônicas institucionais que estão longe de ser estáveis (cf. Whitley, 1984; Hermanowicz, 2009). Universidades respondem a demandas de mudanças societais, especialmente pelos estudantes preferirem certas disciplinas a outras, e a mudanças políticas. As equipes acadêmicas tendem a crescer (ou declinar) alinhadas com as áreas para onde vão os estudantes, ou às quais os governos definem suas prioridades de investimentos, ao menos no longo prazo. Os campos disciplinares, portanto, articulam processos sociais tanto sobre níveis individuais quanto coletivos. Eles emergem como resultado de muitos acadêmicos buscando carreiras acadêmicas sob condições de mudança social, econômica e política (HAMANN, 2018) ${ }^{1}$.

Ranqueamentos entre profissões ou campos do saber, entre instituições (escolas ou universidades públicas $x$ privadas, a partir de provas sistêmicas nacionais), hierarquização entre estados (Ranking de Competitividade dos Estados) e nações, como os decorrentes do PISA (Programa Internacional de Avaliação dos Estudantes; no original, Programm for international Student Assessment, da Organização de Cooperação e Desenvolvimento Econômico, OCDE) norteiam a atribuição de benesses (as bonificações) aos melhores, enquanto expõem fragilidades dos menos qualificados (relegando-os a posições inferiores, em que recebem menos investimentos). Essas formas de cobrança e de avaliação a partir de parâmetros externos mostram-se, contemporaneamente, como geradoras de grande estresse e competitividade em cada um desses âmbitos (institucional ou individual) e, no caso dos professores, em vários estados brasileiros, funcionam como um dos elementos reguladores da progressão na carreira docente. Nesse sentido, em entrevista a Carlota Boto (2018), o educador português António Nóvoa, assertiva e acertadamente, pondera que:

A respeito das políticas educativas, é fácil verificar que estão, hoje, baseadas em uma lógica de exposição pública dos resultados, muito visível com o sucesso global do Programme for International Student Assessment(PISA), da Organização para a Cooperação e Desenvolvimento Econômico (OCDE). Todos esses discursos têm 
como ponto forte a importância dos professores e da sua valorização. Também no Brasil, quem quiser receber uma salva de palmas de uma audiência, declara o seu amor à escola básica e aos professores. Mas o que se verifica na realidade? Uma desvalorização dos professores, e do seu estatuto profissional, em quase todos os países do mundo, e muito notoriamente no Brasil. (NOVOA, 2018 apudBOTO, 2018, p. 14).

Tardif e Lessard (2005, p. 27) destacam que

[u]ma profissão, no fundo, não é outra coisa senão um grupo de trabalhadores que conseguiu controlar (mais ou menos completamente, mas nunca totalmente) seu próprio campo de trabalho e o acesso a ele através de uma formação superior, e que possui uma certa autoridade sobre a execução de suas tarefas e os conhecimentos necessários à sua realização.

Dessa forma, o magistério deve ser reconhecido como categoria profissional com identidade própria, um ethos constituído que prevê rituais de ação, formas preconizadas (e, em consequência, também as formas a serem evitadas) de atuação e de relação com o público que caracteriza o alvo da ação pedagógica intencional, planejada e direcionada. Assim sendo, apresenta também uma dimensão epistêmica e metodológica específica (um saber acadêmico, um saber da vivência prática, etc.) que não é trivial, numa sociedade complexa e em constante mudança política, socioeconômica, tecnológica, cultural.

Tudo isso faz pressupor a exigência de qualificação continuada, de investimento e verticalização dos estudos, o que se plasma de forma apropriada num contexto de valorização (reconhecimento social e remuneratório) dessa mesma categoria. No entanto, a profissionalização docente não é um processo linear, mas historicamente atravessado por disputas e conflitos, em meio a avanços e recuos. A profissionalização exigida vem sendo caracterizada por um alto nível de cobrança que promove, desde o final dos anos 1990, a "universitarização" da formação, nos termos de Nóvoa (2017), visto que, mesmo para a docência nos níveis iniciais da Educação Básica, passa-se a exigir a habilitação em nível superior. Ao mesmo tempo, observa-se a crescente transformação da formação docente em objeto de pesquisa, com a finalidade de criar estratégias, instrumentos e adaptações curriculares de modo a aprimorá-la e a promover melhoria qualitativa da educação básica. Mas, paradoxalmente, ao lado de tais exigências e estudos, Nóvoa (2017), respaldado por diversos estudiosos, salienta que:

Desde o início do século [XXI], percebe-se um sentimento de insatisfação, acentuado por políticas de desprofissionalização, de ataque às instituições universitárias de formação docente e de privatização da educação (ZEICHNER, 2010a). Em conjunto, estas tendências configuram "um programa de reforma educacional baseado nos princípios de mercado das economias neoliberais" (COCHRAN-SMITH et al., 2015, p. 117). A desprofissionalização 
BARROS, E. B. R. de.; SANTOS, L. de.

manifesta-se de maneiras muito distintas, incluindo níveis salariais baixos e difíceis condições nas escolas, bem como processos de intensificação do trabalho docente por via de lógicas de burocratização e de controlo. O discurso da eficiência e da prestação de contas tem reforçado políticas baseadas em "medidas de valor acrescentado", que remuneram os professores em função dos resultados dos alunos, desvalorizando assim outras dimensões da profissionalidade. (NOVOA, 2017, p. 1109).

É preciso lembrar que a profissionalização docente é situada, isto é, ocorre num contexto geopolítico, histórico-social e econômico específico - e, portanto, é fruto dessa teia de fatores interdependentes. Enguita (1991) discute de forma aprofundada os efeitos do capitalismo sobre todo o percurso de profissionalização docente, o qual implicou uma série de demandas e atribuições ao professor que, desprovido dos meios de produção (materiais e simbólicos), vê-se compelido a uma proletarização, esta, a seu turno, expropria-o dos recursos necessários a seu projeto de construção de carreira, obriga-o a agir de determinada maneira, a praticar um currículo elaborado fora e alheio às demandas dos grupos sociais com os quais trabalha ${ }^{2}$ em prol de um suposto projeto coletivo de escola. Despojado da capacidade de gerir todo o processo educativo (planejamento, execução, monitoramento e avaliação), o professor vê seu trabalho passar por um processo de proletarização, ainda que não deixe de ser um profissional do fazer intelectual (dadas as características de sua ação de ensino), mas de quem se cobra tarefas rotinizadas e controladas, aprofundando o processo de desprofissionalização e desvalorização do trabalho docente (BARROS; SANTOS, 2019).

Martins (2013, p. 11901) salienta que essa contradição é perceptível, no Brasil, "no discurso dos dirigentes de organizações da sociedade civil e das autoridades governamentais" de todos os entes federativos, que diante das demandas sociais praticamente jogam nas mãos dos professores a responsabilidade pela melhoria da qualidade do ensino público, amplamente criticado nos diversos canais midiáticos. No entanto, trata-se de uma falácia, uma forma perversa de ocultar os verdadeiros fatores responsáveis pela aguda desigualdade social, que leva a desiguais possibilidades de aprendizagem, de acesso a bens culturais e de oportunidades no mercado (de trabalho e de remunerações) e que, em última instância, visam à maximização dos lucros no mercado educacional.

Labaree (1999 apudIMBERNÓN, 2011, p.11-12) afirma que:

Há uma série de razões para crer que o caminho para a profissionalização dos docentes encontra-se cheio de crateras e areias movediças: os problemas próprios que surge ao tentar promover os critérios profissionais dentro de uma profissão tão massificada, a possibilidade de desvalorização das habilitações como consequência do aumento dos requisitos educativos, a herança niveladora dos sindicatos dos professores, a posição histórica da docência como forma de trabalho própria de mulheres, a resistência que oferecem os pais, os cidadãos e os políticos à reivindicação do controle profissional das escolas, o fato de a docência ter demorado a se incorporar a um campo infestado de trabalhos profissionalizados, a prévia profissionalização dos 


\begin{abstract}
administradores das escolas e o excessivo poder da burocracia administrativa, a prolongada tradição de realizar reformas educacionais por meios burocráticos [...] e a diversidade de entornos em que se dá a formação dos professores. (LABAREE, 1999, p.20 apudIMBERNÓN, 2011, p. 11-12).
\end{abstract}

Sua síntese do contexto de final de século XX, para a realidade espanhola, apresenta muitas aproximações com a realidade atual no Brasil, em que vários fatores se entrelaçam no processo de escolha, formação e profissionalização do professor, sobretudo neste momento em que se promove a exacerbação da massificação, a desvalorização da representatividade sindical, agudizando a precarização das condições de trabalho dessa profissão.

Assim, Imbernón (2011) salienta que, contemporaneamente, como característica primordial, a profissionalização demanda uma "capacidade reflexiva em grupo", não como forma de implementar ou aprimorar atuação técnica, mas como um "processo coletivo para regular as ações, os juízos e as decisões sobre o ensino, já que o mundo que nos cerca tornou-se cada vez mais complexo, e as dúvidas, a falta de certezas e a divergência são aspectos consubstanciais" (IMBERNÓN, 2011, p. 15) com que todos os que atuamos na educação inexoravelmente convivemos. Ele reitera que esse processo implica uma série de rupturas (com certas tradições, com a inércia e certas ideologias impostas) e, paralelamente, a assunção de novos posicionamentos (como a "autonomia profissional compartilhada") e novas relações (mais coletivas, já que o isolamento vulnerabiliza a todos).

A despeito do expressivo crescimento das pesquisas e de maior investimento em políticas públicas de formação docente nas últimas décadas, ainda persiste uma insatisfação generalizada com a qualidade da formação inicial dos professores, situação que ultrapassa a realidade brasileira e pode ser verificada em diferentes países:

Ministérios da Educação, docentes em exercício, formadores de docentes, pesquisadores e também candidatos a docentes e empregadores põem em dúvida a capacidade das universidades e institutos de formação docente de dar resposta às necessidades atuais da profissão. As críticas referem-se à organização burocratizada da formação, ao divórcio entre teoria e prática, à excessiva fragmentação do conhecimento que se socializa e à escassa vinculação com as escolas. (VAILLANT; MARCELO, 2012, p. 63).

Embora autores como Nóvoa $(2017,2018)$ assinalem o quanto se tem pesquisado e discutido a formação de professores, especialmente na academia, nos congressos e periódicos científicos da área da Educação, assiste-se, em dimensão expressiva, a grande retrocesso nas políticas públicas para a área, a certa estagnação no desenvolvimento das instituições formadoras, que se veem incapazes de verdadeira inovação/renovação, de modo a acompanhar as mudanças sociais e tecnológicas e fazêlas chegar à formação de professores e, em decorrência, à ambiência escolar. 
BARROS, E. B. R. de.; SANTOS, L. de.

\section{FORMAÇÃO DOCENTE INICIAL: RESSIGNIFICANDO TEORIAS E PRÁTICAS EDUCATIVAS}

Sobre profissionalidade docente, Gimeno-Sacristán (1993) ressalta a "especificidade da atuação dos professores na prática, isto é, o conjunto de atuações, destrezas, conhecimentos, atitudes e valores ligados a elas que constituem o específico de ser professor" (GIMENO-SACRISTÁN, 1993, p. 54). Isso não se consolida por meio dos estudos universitários apenas, pois a competência necessária para o reconhecimento do profissional como um expert (no sentido mais amplo desse termo: aquele que tem uma expertise ou domínio sobre aquilo que faz) é algo que se vai conquistando em diferentes etapas e por meio da assunção de diferentes papéis (gestão do conhecimento, da sala de aula, das relações interpessoais, etc.).

Ao falar da necessária mudança a ser implementada na formação inicial e continuada para que o "professor do século XXI" compreenda o que se espera do seu próprio fazer, uma prática que é visceralmente diferente do que se esperava do professor do século passado, Imbernón lembra que:

\footnotetext{
Há de ser abandonado o antiquado conceito de racionalidade técnica de que a formação é a atualização científica, didática e psicopedagógica do professorado pela crença de que a formação ajudará a descobrir a teoria, ordená-la, fundamentá-la, revisá-la e construí-la. Se fizer falta, ajudará a remover o sentido pedagógico comum, recompor o equilíbrio entre os esquemas práticos predominantes e os esquemas teóricos.

Este conceito parte da base de que o professorado é construtor de conhecimento pedagógico de forma individual e coletiva. É um conceito de racionalidade prática e emancipadora. A formação técnica e isolada pode originar experiências de inovação, mas dificilmente uma inovação da instituição e da prática coletiva dos profissionais. Temos que aproximar ao máximo a formação aos centros e aos espaços, partindo das necessidades reais do professorado. (IMBERNÓN, 2012, p. 46. Grifos nossos.).
}

Essa fala de Imbernón, em entrevista concedida a Sudbrack (2012), nos lembra que existem práticas formativas que efetivamente podem reconfigurar a tão problemática relação teoria-prática, alvo de severas críticas quanto à formação teórica advinda da academia. E um grau mais elevado de autopercepção e de percepção dos meandros do trabalho docente não vem num insight - é construído em meio ao labor na escola, como campo de atuação, de vivência de relações, de instauração de uma carreira.

Cabe ainda trazer a voz desse pesquisador espanhol quando afirma que a aquisição de conhecimentos pelo professor é um processo situado, ou seja, uma formação que "está muito ligada à prática profissional e condicionada pela organização da instituição educacional" em que exerce seu papel. Assim, é crucial que haja o desenvolvimento de uma formação em serviço, no interior da escola:

Como a prática educativa é pessoal e contextual, precisa de uma formação que parta de suas problemáticas. Na formação não há problemas genéricos para todos nem, portanto, soluções para 
todos; há situações problemáticas em um determinado contexto prático. Assim o currículo de formação deve consistir no estudo de situações práticas reais que sejam problemáticas. (IMBERNÓN, 2011, p. 17).

Num cenário em que poucos jovens manifestam interesse pelo magistério e quando o fazem por vezes são desestimulados, inclusive por professores já com carreira consolidada, diante dos inúmeros desafios cotidianos, que demandam certa resiliência para enfrentá-los, políticas públicas indutoras da formação inicial e promotoras da formação continuada são extremamente necessárias e bem-vindas, desde que sejam capazes de promover uma ampla reconfiguração da formação e que possibilitem (res)significar determinadas práticas.

Nesse sentido, desde 2007 o Programa Institucional de Bolsas de Iniciação à Docência (Pibid) vem se constituindo num marco consistente em relação à fixação de graduandos nas licenciaturas, à promoção da adesão de jovens egressos às escolas públicas, à aproximação teórico-prática e metodológica tão necessária para minimizar o "choque de realidade" quando do ingresso no universo da sala de aula e da ambiência escolar. Compreendemos que o Pibid (e, mais recentemente, também o Programa Residência Pedagógica) constitui-se numa política de formação na e para a prática docente, que tem como pilares formativos a inserção de licenciandos no cotidiano das escolas públicas de educação básica e a constituição de redes de colaboração e projetos de parceria entre as Instituições de Ensino Superior (IES) e as escolas de Educação Básica.

No que diz respeito aos professores formadores dos cursos de licenciatura, de acordo com Gatti et al. (2019), diversos fatores da formação inicial são alvo de críticas, mas "o mais obscurecido no bojo das discussões e pesquisas no campo da formação docente é o formador" (p. 271). Para elas,

\begin{abstract}
Ainda se sabe pouco a respeito desse profissional e, portanto, da sua formação, das suas experiências na educação básica e no ensino superior, dos tempos de dedicação, da remuneração e condições de trabalho, das oportunidades disponíveis para 0 seu desenvolvimento profissional e acadêmico, das suas concepções de educação e de formação e das suas práticas. (GATTI et al., 2019, p. 272).
\end{abstract}

Ao investir na construção de diálogos e na partilha de responsabilidades entre formadores dos cursos de licenciatura e professores da Educação Básica, estes últimos são também protagonistas importantes e coformadores dos licenciandos. Nota-se, portanto, a complexidade do tema, já que o estudo das práticas dos agentes formadores, no processo de formação inicial ou continuada de professores, revela intrincada rede de desafios e dilemas que emergem do cotidiano de trabalho - tanto na escola básica quanto na universidade. Assim, estudos que visam a compreender as percepções, crenças, opiniões e representações dos docentes (GATTI et al., 2019; TARDIF; LESSARD, 2005; BARROS, 2015) permitem descortinar como se constroem os 
conhecimentos profissionais (epistemológicos e metodológicos) desses formadores e as (re)significações que a eles são atribuídas.

A outra ponta da triangulação - os jovens professores formados a partir desse consórcio de ações entre as duas instâncias formadoras - também desperta grande interesse e assume relevância. Assim, a pesquisa cujos resultados aqui aduzimos visou a contribuir para a compreensão dos desafios e obstáculos enfrentados por um grupo de egressos do Pibid, muitos dos quais atualmente ingressos na carreira, mapeando, simultaneamente, representações e percepções sobre o significado da participação neste Programa.

O QUE REVELAM AS NARRATIVAS DE EGRESSOS DE UMA POLÍTICA PÚBLICA INDUTORA SOBRE A FORMAÇÃO INICIAL

Os depoimentos e análises que apresentamos neste artigo decorrem de uma pesquisa interinstitucional ${ }^{3}$ que agrega pesquisadores de diversos departamentos e teve como foco licenciados que se formaram no período de 2012 a 2018, oriundos de quatro Instituições de Ensino Superior (IES) mineiras, e que haviam participado do $\mathrm{Pibid}^{4}$. A partir de um questionário construído no Google forms (divulgado por meio de e-mails aos egressos e também nas redes sociais dos pesquisadores), o qual continha 23 questões fechadas e 4 questões abertas, foi possível reunir dados sobre o perfil, trajetória de formação e ingresso (ou não) na carreira docente de 103 recém-egressos das licenciaturas, participantes da pesquisa. Os dados obtidos, especialmente as narrativas produzidas em resposta às questões abertas, nos possibilitaram compreender alguns dos impactos da participação neste Programa para a sua formação e atuação profissional, bem como sobre algumas concepções e práticas de docência, a relação com a escola pública e sua perspectiva de permanência na profissão.

Autores como Suárez (2007) e Goodson (2008) defendem o potencial de investigações centradas nas narrativas docentes, enquanto oportunidade para aprofundar nossos entendimentos sobre a vida e o trabalho dos professores/as. Dialogando com Suárez (2007), Almeida Jr. (2011) nos diz que:

\footnotetext{
As escolas estão repletas de histórias e os professores são, ao mesmo tempo, os autores/atores e contadores dessas diversas tramas e enredos. Em um processo de produção de narrativas, ao narrarem e serem narrados, os docentes recriam cotidianamente sentidos do exercício da docência e da escolarização e, nesse movimento, reafirmam ou reconstroem sua identidade coletiva profissional. (ALMEIDA JR., 2011, p. 65).
}

As respostas abertas do questionário propiciaram a constituição de um vasto e rico material empírico, evidenciando significativa disposição dos sujeitos investigados em partilhar experiências, empreender análises e reflexões. Dessa forma, a partir das narrativas de jovens professores, buscou-se conhecer, discutir e refletir sobre alguns dos sentidos e significados produzidos por estes sujeitos acerca de suas experiências formativas e os desafios enfrentados nos primeiros anos de magistério.

Sendo uma pesquisa de natureza qualitativa, abraçamos o princípio definido por Bogdan e Biklen (1994, p. 50) de que "[o] significado é de importância vital na 
abordagem qualitativa". Ainda que não tenhamos a pretensão de exaurir o tema, ou mesmo de generalizar as conclusões para egressos de outras IES mineiras ou brasileiras, este estudo nos permitiu levantar questões e evidenciar aspectos de uma realidade partilhada por muitos jovens professores que participaram do Pibid. A recorrência de situações e aspectos evidenciados pela pesquisa, ao compararmos com outras, recentemente divulgadas, e que tratam do mesmo tema, reforçam a hipótese de que os achados são representativos de algumas das faces das múltiplas realidades da docência no Brasil.

O procedimento metodológico envolveu discussão dos dados quantitativos, compilados e representados em gráficos e tabelas, ao lado da leitura cuidadosa e dialogada das narrativas construídas pelos sujeitos pesquisados; dessa forma, tratou-se de um processo de imersão nos dados, num exercício dialógico e dialético que, segundo Franco (2008), permite "conhecer os textos e as mensagens neles contidas, deixando-se invadir por impressões, representações, emoções, conhecimentos e expectativas" (FRANCO, 2008, p. 52). À luz do aporte teórico, foram definidas categorias e subcategorias de análise que fundamentaram nosso olhar sobre os dados.

As questões fechadas do questionário versaram sobre temas diversos, como identificação dos sujeitos (sexo, idade, estado civil, faixa etária); formação acadêmica (IES em que estudaram, graduação cursada, data da formatura, informações sobre continuidade de estudos em nível de pós-graduação); participação no Pibid (por quanto tempo, qual a contribuição para sua formação); escolha pelo magistério (existência de professores na família e possível influência desses familiares; motivos da escolha pela profissão); inserção na docência (se estão atuando, já atuaram ou nunca ingressaram na profissão e quais os motivos para essa situação); contextos e condições de trabalho de quem está atuando (há quanto tempo, em qual rede de ensino - pública: federal, estadual ou municipal - ou particular), nível de atuação na Educação Básica (Fundamental I ou II, Ensino Médio), regime de trabalho (efetivo, contratado, "designado", outro), carga horária semanal de aulas/distribuição por turnos (tempo médio semanal dedicado a estudos, a planejamentos e a avaliação de trabalhos).

Entre os 103 pesquisados, 74 (71,8\%) eram mulheres, enquanto $29(28,2 \%)$ eram homens. De acordo com o Censo Escolar da Educação Básica de $2017^{5}$, as mulheres constituíam $80 \%$ dos docentes de Educação Básica no país. Quando indagados sobre a existência de professores na família, 52\% dos pesquisados confirmaram ter parentes professores, especialmente tios e primos, mas também pais e irmãos. No entanto, apenas $11 \%$ dos que afirmaram ter parentes professores consideram que esses familiares teriam influenciado muito sua escolha pelo curso de licenciatura. Quanto às principais motivações para a escolha da profissão docente, entre um rol de alternativas apresentado, quase $60 \%$ dos pesquisados assinalou "Por gostar de dar aulas", enquanto a alternativa "Prestígio/reconhecimento social" foi assinalada por menos de $4 \%$ deles, confirmando a clara percepção desses sujeitos de estarem ingressando em uma profissão de baixo prestígio social, conforme discutido na primeira parte deste artigo. Houve maior concentração de respondentes que cursaram licenciatura na PUC Minas (36\%) e UEMG (33\%), enquanto um percentual menor de participantes era oriundo da UFMG $(15,5 \%)$ e da UFSJ (14,5\%). Os participantes provinham de 14 diferentes 
BARROS, E. B. R. de.; SANTOS, L. de.

licenciaturas, com maior representatividade dos cursos de Ciências Biológicas, Pedagogia e História, que somaram mais de $50 \%$ dos participantes. Esses sujeitos tinham, em média, 2 a 3 anos de formados, sendo que 16 deles (15,5\%) afirmaram nunca ter atuado como professores; 60 deles (58,3\%) estavam exercendo a docência e 27 $(26,2 \%)$ disseram já ter atuado, mas não estavam exercendo a docência no momento da pesquisa. A grande maioria dos que nunca tinham atuado, ou que não estavam atuando no momento da pesquisa, apontou, como principal causa para essa situação, o fato de não terem conseguido trabalho no magistério.

Era nossa intenção saber se a participação no Pibid era reconhecida como um fator de adesão à profissão, à escola pública, e capaz de atenuar o chamado "choque de realidade" que acomete os profissionais em início de atuação profissional, temas que foram tratados nas questões abertas do questionário, as quais indagavam sobre: as contribuições do Pibid para a formação; as experiências significativas e aprendizados considerados relevantes durante a participação no Programa; experiências e desafios vivenciados no início da carreira docente; aprendizados construídos na formação (especialmente no Pibid) que teriam contribuído de forma mais significativa para minimizar possíveis dilemas, conflitos e dificuldades característicos do início da vida profissional. Uma última questão abria espaço para comentários e temas não contempladas nas perguntas anteriores.

As respostas ao questionário - tanto as fechadas quanto as abertas - trouxeram inúmeras evidências da relação entre uma política pública de formação docente e o processo de inserção na carreira docente, salientando-se a compreensão de que o ingresso na carreira é fortemente atravessado pelas condições efetivas de trabalho, pela cultura e pelo clima institucional, entre outros fatores.

Vários aspectos foram reiterados por meio das narrativas dos novos professores: um deles, bastante recorrente, trata da relevância atribuída pelos egressos à partilha vivenciada no programa, em que se sentiam confortáveis por se apoiarem tanto no grupo de colegas quanto nos saberes dos professores mais experientes (o supervisor da escola-campo e o coordenador de área, da universidade). Essa constatação nos remete a Nóvoa (2019), para quem a constituição de "comunidades de prática" ou "comunidades de aprendizagem", por meio de uma parceria entre professores formadores das licenciaturas e professores experientes (que atuam nas escolas parceiras, da Educação Básica), como coformadores dos novos docentes, cria um ambiente propício para a adesão dos novos professores ao magistério, amortecendo o chamado "choque de realidade ${ }^{\prime 6}$ e permitindo um processo de profissionalização baseado na colaboração e na cooperação entre os envolvidos, produzindo um clima escolar mais positivo, com efeitos claros inclusive na relação docente-discentes:

É esta co-responsabilidade que permite construir uma verdadeira formação profissional. Para que ela tenha lugar, é necessário atribuir aos professores da educação básica um papel de formadores. A construção de uma parceria exige uma compreensão clara das distintas funções, mas sempre com igual dignidade entre todos e uma capacidade real de participação, isto é, de decisão. (NÓVOA, 2019, p. 206). 
Essa "colegialidade docente", isto é, a possibilidade de os professores atuarem como um coletivo tem tanto uma referência organizacional (o projeto educativo da escola) quanto uma referência pedagógica (a construção de novos ambientes educativos), permitindo a construção de "comunidades de trabalho" ou "comunidades profissionais", o que minimiza efeitos perversos da precarização e proletarização do trabalho docente, como já apontamos, e que foram confirmados pelas narrativas dos egressos, sujeitos desta pesquisa.

O trabalho coletivo tem sido amplamente reconhecido como fator de aperfeiçoamento e apoio ao trabalho docente, e pode ser ainda mais crucial nos anos iniciais de imersão na carreira, "os mais decisivos na vida profissional docente, pois marcam, de muitas maneiras, a nossa relação com os alunos, com os colegas e com a profissão. É o tempo mais importante na nossa constituição como professores, na construção da nossa identidade profissional" (NÓVOA, 2019, p. 1999). Essas análises podem ser transferidas para os anos que antecedem o efetivo ingresso na carreira, durante o processo de indução profissional.

O Pibid pode ser pensado, assim, a partir do que Nóvoa (2019) denomina como um "entrelugar", ou seja, "período entre-dois, entre a formação e a profissão", momento que pode conferir um elevado valor à formação docente, visto que se presta "à indução profissional, através da residência docente ou de outras iniciativas, um tempo que é estruturante do desenvolvimento profissional docente." (NÓVOA, 2019, p. 207).

Nesse sentido, perfilam-se alguns depoimentos dos participantes da pesquisa que evidenciam o reconhecimento desses sujeitos quanto à importância das parcerias e trocas estabelecidas com colegas e com professores formadores, para a qualificação de sua formação, neste "tempo entre-dois":

\footnotetext{
"A maior contribuição foi a oportunidade de acompanhar docentes diferentes, com estilos diferentes e atuação em escolas diferentes, o que me proporcionou uma perspectiva da diversidade das formas de ser professor." (UFMG, Ciências Sociais) ${ }^{7}$.
} "Realizar trabalho e atividades coletivas, respeitando e interagindo
com as dificuldades e qualidades de cada um." (UEMG/BH, Música).

\begin{abstract}
"Aprendi o valor do trabalho em equipe, a troca com pessoas de níveis de conhecimento diferentes e tive a oportunidade de ter a noção de como é a rotina e quais são os desafios enfrentados nas escolas públicas." (UEMG/BH, Artes Plásticas).

"Para mim o mais significativo foi a possibilidade de trabalhar com profissionais de outras áreas dentro do ambiente escolar, a experiência interdisciplinar é muito rica e nos encontros acredito que compartilhávamos o que aprendíamos de maneira dinâmica, o que possibilitava dicas, novos ensinamentos etc." (PUC Minas, História).
\end{abstract}

“O Pibid é uma maneira de ter experiência em ser professor tendo todo o acompanhamento de professores mais experientes que 
BARROS, E. B. R. de.; SANTOS, L. de.

podem te orientar antes de assumir a responsabilidade sozinho. Além disso, houve uma troca de relatos e experiências entre os bolsistas que considerei bastante significativo na minha formação." (UFSJ, Ciências Biológicas).

Os depoimentos trazem indícios de que o contato positivo com professores experientes, sejam os supervisores, sejam outros da escola, pode suscitar um ambiente mais acolhedor e minimizar o sentimento de desamparo que acomete muitos jovens professores, ainda durante o processo de formação - nos Estágios Supervisionados, por exemplo. A troca de experiências também parece ser um dos elementos que permite uma inserção na docência mais sustentada por elementos constituintes da cultura profissional, afastando, de certa forma, a sensação de "ensaio e erro" que perpassa os primeiros anos de ingresso na carreira de inúmeros professores. A possibilidade de partilha de saberes e fazeres, internamente, nas equipes, parece atenuar a perplexidade diante de vários desafios cotidianos que se apresentam à ação docente.

Sobre as múltiplas tarefas e ações que caracterizam o trabalho dos professores e os aprendizados a ele relacionados, vejamos mais algumas das narrativas partilhadas pelos sujeitos investigados:

“O Pibid me ajudou muito nos planejamentos de aulas, tínhamos a professora da escola que nos acompanhava e nos passava suas experiências. Me sentia insegura com as aulas na Universidade, ansiosa e com medo de enfrentar a sala de aula. O Pibid tirou a ansiedade e me mostrou como planejar, como refletir minhas práticas pedagógicas e como me avaliar a cada dia. Me ensinou a aliar a teoria à prática e a refletir sobre a forma de aprender de cada aluno. Foram muitas as contribuições, desde a prática dentro das escolas, o convívio e receptividade dos professores das escolas, o carinho e aceitação das crianças. Como também as orientações dos professores coordenadores da universidade, as leituras, seminários, rodas de conversas, tudo muito rico e importante na minha há formação como professora." (UEMG/BH, Pedagogia).

"A experiência mais significativa se deu quando auxiliamos na organização de um evento sobre relações de gênero no colégio estadual central, e tivemos oportunidade de nos envolver tanto na organização da logística do evento dentro da escola quanto ministrando uma oficina, o que me incentivou a pensar em formas de realizar eventos em formato parecido na escola em que leciono agora. (UFMG, Ciências Sociais).

"O Pibid foi muito importante na minha jornada acadêmica. Porque vejo que o programa foi a experiência mais próxima que pude ter, da realidade escolar. Consegui vivenciar um pouco do que realmente é ser professor, do que realmente é a realidade, claro com algumas ressalvas, porquê não é a mesma coisa de você chegar sozinho em uma escola e ter que enfrentar muitos dos dilemas do início da docência sozinho. Mas estando no Pibid pude ter experiência em várias esferas, pude participar do planejamento do conteúdo, da organização dos planos de aula, de unidades 


\begin{abstract}
didáticas, de desafios que surgem durante o dia a dia, puder ver o funcionamento da escola, que muitas vezes em um estágio não conseguimos ver. Sendo responsável por uma turma, pude fazer minha primeira prova, criar trabalhos, pontuar os alunos, pensar como um verdadeiro professor, existia uma autonomia que trouxe muito aprendizado. Mas tudo isso aconteceu com a supervisão de, no meu caso, uma professora. Então existia uma troca, existia um aprendizado após fazer todas essas coisas, porque teria alguém junto para avaliar, para dar sugestão, alguém que já tinha bastante experiência. Foi incrivel participar do PIBID, tive esse privilégio." (UFMG, Educação Física).
\end{abstract}

Uma das maiores críticas que se fazem à formação nos cursos de licenciatura reside na dissintonia entre a teoria e prática, como se os licenciandos fossem formados para um futuro idealizado, sem convergência com os inúmeros desafios da prática no "mundo real". Assim, a inserção (o mais precoce possível) dos graduandos no cotidiano escolar, em "comunidades de aprendizagem" concretas, em uma vivência permeada pela interdisciplinaridade e pela coletividade, parece favorecer uma aprendizagem ressignificada, como ressaltam os depoimentos selecionados. Esta parece favorecer uma maior adesão à carreira, ainda que com a consciência dos desafios:

\begin{abstract}
"A participação no Pibid foi essencial para que eu confirmasse meu desejo de ser professora, uma vez que pude interagir com adolescentes no ambiente escolar. Além disso, os projetos desenvolvidos me ensinaram a como fazer um planejamento didático efetivo e as maneiras possíveis de colocá-lo em prática." (PUC Minas, Letras).
\end{abstract}

O reconhecimento de que experiências positivas vivenciadas durante a formação favorecem a escolha e pavimentam o caminho de ingresso e permanência no magistério não pode obscurecer o fato de que, a despeito do desejo - construído - de se tornar professor, o contexto de inserção profissional e as reais condições de exercício do magistério serão fatores de grande relevância para a permanência, ou não, na profissão. Infelizmente, o crescente processo de desvalorização social e salarial e a precarização das condições de trabalho têm expulsado muitos jovens com uma promissora carreira no magistério. Até quando a docência continuará perdendo jovens talentos e negando a muitos deles a possibilidade de oferecerem o seu melhor desempenho profissional?

\title{
CONSIDERAÇÕES FINAIS
}

São muitas as vozes e as ressonâncias que ecoam dos dados, de forma bastante lúcida, a despeito da pouca experiência dos participantes no universo da docência. Sem a pretensão de exaurir os dados apresentados, procuramos sinalizar algumas das percepções desses jovens professores sobre a formação vivenciada no Pibid, os dilemas do início de carreira e suas perspectivas de permanência - ou não - no magistério. Muitos desses jovens licenciados evidenciam ter "se descoberto" na relação com os 
alunos, na relação com os colegas (professores em exercício e demais participantes das equipes), na compreensão de que há diferentes formas e ritmos de ensino e de aprendizagem e de que é preciso investir para desenvolver novas (inovadoras) metodologias. E tais descobertas parecem estar fortemente vinculadas à experiência que tiveram nesse programa de formação docente, o Pibid.

No entanto, conforme discutimos neste artigo, uma maior qualificação da formação (inicial e continuada) é fator fundamental - mas não exclusivo - no avanço do processo de profissionalização docente (ENGUITA, 1991; BARROS; SANTOS, 2019, entre outros). Diversos aspectos participam e precisam ser considerados para que o avanço se efetive. A valorização social e salarial da profissão; a conquista de melhores condições de trabalho; o reconhecimento de saberes próprios e específicos, construídos e sob domínio de professores experientes; a garantia de participação em instâncias decisórias - relacionadas ao processo educativo, à gestão escolar e às políticas públicas em educação; a constituição e consolidação de fóruns de debate próprios e de associações corporativas com poder de influência e de mobilização da categoria são alguns dos elementos que podem fortalecer a autonomia e afirmação dos professores como categoria profissional, contribuindo para consolidar esse processo - com mais avanços e menos recuos, ainda que não se trate de percurso linear.

Entre esses vários elementos, a questão de um saber próprio, produzido pelos professores e validado socialmente como um corpo de conhecimentos que só aqueles experientes dominam, nos parece um dos aspectos fulcrais para seu reconhecimento como categoria profissional. E ainda que a experiência e trajetória profissional e de formação de cada professor seja única, a sistematização e validação desse corpo de conhecimentos é um processo coletivo, cujos protagonistas são uma categoria inteira e não um indivíduo ou um grupo.

A pesquisa com jovens ingressantes na carreira do magistério, que tiveram a oportunidade de vivenciar, durante sua formação, experiências de trabalho coletivo, trouxe fortes indícios de que interações sistemáticas e significativas com outros professores, sejam estes da Educação Básica ou dos cursos de licenciatura, pode fazer a diferença não apenas para uma melhor qualidade do processo de formação inicial, mas para uma mudança de status quanto à profissionalidade docente. A constituição de "comunidades de aprendizagem" mostrou ser um dos elementos cruciais para o avanço do controle - coletivo - dos processos de trabalho e de conquista de autonomia também partilhada -, aspectos imprescindíveis à caracterização de uma atividade profissional.

A experiência proporcionada por uma política pública de formação docente como o Pibid não é capaz de reverter situações dramáticas de desvalorização social da profissão, ou de criar mecanismos eficientes para o enfrentamento dos inúmeros desafios e dilemas do magistério e da educação, mas algumas das experiências coletivas que vêm sendo empreendidas por sujeitos participantes deste Programa parecem indicar um horizonte de possibilidades, em caminhos promissores, ainda por construir. Haverá interesse político em fomentar essas possibilidades e pavimentar esses caminhos?

Artigo recebido em: 20/08/2020

Aprovado para publicação em: 18/11/2020 
TEACHING PROFESSIONALIZATION: CONNECTION BETWEEN THEORY, EDUCATIONAL PRACTICES AND COLECTIVE WORK IN A PUBLIC TRAINING POLICY

ABSTRACT: This article discusses teachers professionalization, focusing on some of the tensions, disputes, advances and setbacks historically present in the initial training of teachers, through the presentation and discussion of results of a qualitative research developed with 103 egresses of the Institutional Program of Teacher Initiation Scholarships (Pibid) from four universities in Minas Gerais. In dialogue with testimonials from these young teachers, we seek to understand the role and performance of different subjects in initial teacher training, exploring the importance of sharing knowledge and experiences to face some of the teaching career. The research findings confirm the importance of investing in dialogues between universities and basic education schools, and the potentiality of learning communities and other spaces for sharing knowledge to face challenges and historical barriers to the processes of teacher training.

KEYWORDS: Teaching Professionalization. Initial Teacher Training. Pibid. Learning Communities PROFESIONALIZACIÓN DE LA ENSEÑANZA: CONEXIÓN ENTRE LA TEORÍA, LAS PRÁCTICAS
EDUCATIVAS Y EL TRABAJO COLECTIVO EN UNA POLITICA PÚBLICA DE FORMACIÓN

RESUMEN: Este artículo analiza la profesionalización de los docentes, centrándose en algunas de las tensiones, disputas, avances y retrocesos históricamente presentes en la formación inicial de los profesores, a partir de la presentación y discusión de los resultados de una investigación cualitativa desarrollada con 103 egresos del Programa Institucional de Becas de Iniciación al Magisterio (Pibid), de cuatro universidades de Minas Gerais. En diálogo con los testimonios de estos jóvenes profesores, buscamos comprender el papel y el desempeño de las diferentes asignaturas en la formación inicial de los maestros, considerando la importância de compartir conocimentos y experiências para enfrentar algunos de los dilemas que se presentan al inicio de la carrera docente. Los conclusiones de la investigación confirman la importancia de invertir en los diálogos entre las universidades y las escuelas de la educación básica y la potencialidad de las comunidades de aprendizaje y otros espacios de intercambio de conocimientos para hacer frente a los retos y las barreras históricas a los procesos de formación de profesores.

PALABRAS CLAVE: Profesionalización de la Enseñanza. Formación Inicial de Maestros. Pibid. Comunidades de Aprendizaje.

\section{NOTAS}

1 - Do original: "Career choices and research interests are structured by those institutional tectonics which are far from being stable (cf. Whitley 1984; Hermanowicz 2009). Universities respond to changing societal demands, especially to students preferring certain disciplines over 
BARROS, E. B. R. de.; SANTOS, L. de.

others, and to policy changes. Academic staff tends to grow (or decline) in line with where students go or where governments define their funding priorities, at least in the long run. Disciplinary fields therefore articulate social processes on individual as well as collective levels. They emerge as a result of many academics pursuing academic careers under conditions of social, economic and political change. As academics progress in their careers, they enter relationships of proximity and distance with their peers and produce and reproduce boundaries between academic communities (HAMANN, 2018). (Trad. livre das autoras).

2 - Uma das críticas em relação à nova Base Nacional Comum Curricular (BNCC) - que se encontra em fase de implantação - relaciona-se diretamente a esse aspecto: a ausência de real participação da sociedade e dos profissionais da educação nas etapas de planejamento do currículo para o país. 3 - A pesquisa foi submetida e aprovada pelo Comitê de Ética em Pesquisa, por meio da Plataforma Brasil. Envolveu pesquisadores e egressos de cursos de licenciatura de quatro IES: Pontifícia Universidade Católica de Minas Gerais (PUC Minas); Universidade Federal de Minas Gerais (UFMG); Universidade Federal de São João Del Rey (UFSJ); Universidade do Estado de Minas Gerais (UEMG).

4 - A pesquisa não possibilitou o levantamento de dados precisos sobre quantitativo de licenciandos e de participantes do Pibid, em cada uma das IES, no período investigado. Para uma aproximação do percentual alcançado pela pesquisa, sabemos que as quatro IES pesquisadas representam cerca de $10 \%$ do total de IES mineiras que participaram do Pibid até 2018 . Quanto ao quantitativo de bolsistas, dados de 2014, disponibilizados pela CAPES, apontavam a existência de 10.381 bolsistas no estado de Minas Gerais. Considerando, hipoteticamente, que as quatro IES reunissem cerca de 10\% desses bolsistas (pouco mais de 1.000), esta pesquisa, com 103 egressos, representaria cerca de 10\% do número de bolsistas, em Minas Gerais, no ano de 2014.

5 - Foram consultados os documentos "Censo Escolar da Educação Básica - Notas EstatísticasInep/MEC" dos últimos anos. O último deles a trazer dados sobre sexo e idade dos docentes é o de 2017. Nos documentos referentes a 2018 e 2019, estes dados não são disponibilizados.

6 - Para Veenman (1984), o "choque de realidade" caracteriza a primeira fase de contato de muitos docentes com a profissão; diante de uma inserção profissional marcada pela angústia resultante das complexidades da carreira, da multiplicidade de saberes e competências requeridas e, normalmente, do sentimento de grande isolamento, muitos tendem a desistir do magistério. Veenman e outros autores sugerem que o ideal seria o acompanhamento dessa inserção, à semelhança do que ocorre na "residência médica".

7 - Para garantir o anonimato dos participantes e atender a critérios estabelecidos pelo Comitê de Ética em Pesquisa, os trechos transcritos indicam apenas a IES e curso de origem dos depoentes.

\section{REFERÊNCIAS}

ALMEIDA JR., Admir Soares de. Foto e Grafias: narrativas e saberes de professores/as de Educação Física. Campinas, SP: Universidade Estadual de Campinas (Tese de Doutorado), 2011.

ANGERMULLER, J.; HAMANN, J. (2019). The celebrity logics of the academic field. The unequal distribution of citation visibility of Applied Linguistics professors in Germany, France, and the United Kingdom. Journal for Discourse Studies, 1 p. 77-93.

BARROS, Ev'Angela B. R. de. Representações, valores e crenças em discursos de professores da educação básica e implicações na (form)ação docente. SCRIPTA, Belo 
Horizonte, v. 19, n. 36, p. 201-227, $1^{\circ}$ sem. 2015. Disponível em: http://periodicos.pucminas.br/index.php/scripta/article/view/10021/0. Acesso em: 05 ago.2020.

BARROS, Ev' Ângela. B. R. de; SANTOS, Lorene dos. Identidade docente. A diferença entre "ser um profissional" e "comportar-se profissionalmente". Revista Presença Pedagógica. v. 1, p. 20-26, 2019.

BOGDAN, R, C. ; BIKLEN, S. K. Investigação qualitativa em educação: uma introdução à teoria e aos métodos. Porto (Portugal): Porto Editora, 1994.

BOTO, C. António Nóvoa: uma vida para a educação. Educação e Pesquisa [online]. 2018, vol.44, Epub Nov 23. https://doi.org/10.1590/s1678-4634201844002003. Disponível em: https://www.scielo.br/scielo.php?script=sci_issuetoc\&pid=1517970220180001. Acesso em: 17 ago.2020.

ENGUITA, M. 1991. A ambiguidade da docência: entre o profissionalismo e a proletarização. Teoria e Educação, Porto Alegre, n. 4: p. 41-61.

FRANCO, M. L.P. B. Análise do Conteúdo. Brasília: Líber Livro Editora, 2008.

GATTI, B. A. et al. Professores do Brasil. Novos cenários de formação. Brasília: Edições UNESCO, 2019.

GOODSON, Ivor F. As políticas de currículo e de escolarização: abordagens históricas. Petrópolis: Vozes, 2008.

IMBERNÓN, F. Formação docente e profissional: formar-se para a mudança e a incerteza. São Paulo: Cortez, 2011.

OLIVEIRA, D. A. A nova regulação de forças no interior da escola: carreira, formação e avaliação docente. RBPAE - v.27, n.1, p. 25-38, jan./abr. 2011.

MARTINS, P. F. de M. Profissão e carreira docente: um debate necessário No processo de melhoria da qualidade da educação. XI Congresso Nacional de Educação EDUCERE. Anais.... p.11900-11914. Disponível em: https://educere.bruc.com.br/ANAIS2013/pdf/9076_5672.pdf. Acesso em: 10 ago. 2020.

NOVOA, A. Firmar a posição como professor, afirmar a profissão docente. Cadernos de $\begin{array}{lllllll}\text { Pesquisa } & \text { v.47 } & \text { n.166 } & \text { p. } & 1106-1133 & \text { out./dez. }\end{array}$ http://dx.doi.org/10.1590/198053144843. Disponível em: http://www.scielo.br/scielo.php?script=sci_arttext\&pid=S010015742017000401106\&lng=en\&nrm=iso. Acesso em: 10 ago. 2020. 
BARROS, E. B. R. de.; SANTOS, L. de.

NOVOA, A. ENTRE A FORMAÇÃO E A PROFISSÃO: ensaio sobre o modo como nos tornamos professores. Currículo sem Fronteiras, v. 19, n. 1, p. 198-208, jan./abr. 2019. Disponível em: http://www.curriculosemfronteiras.org/vol19iss1articles/novoa.html Acesso em: 12 ago. 2020.

SUÁREZ, D. Documentación Narrativa e Experiencias y Viajes Pedagógicos. Fasciculo 2. Qué es la Documentación Narrativa de Experiencias Pedagógicas? Ministerio de Educación, Ciencia y Tecnologia. Laboratorio de Politicas Públicas. Buenos Aires, 2007.

SUDBRACK, E. M. Formação permanente e carreira docente: Francisco Imbernón Muñoz, Entrevista com o professor Dr. Francisco Imbernón Muñoz. R. de Ciências Humanas, 2012, Frederico Westphalen v. 13 n. 20. Disponível em: http://revistas.fw.uri.br/index.php/revistadech/article/viewFile/352/63. Acesso em: 12 ago. 2020.

TARDIF, M.; LESSARD, C. O trabalho docente: elementos para uma teoria da docência como profissão de interações humanas. Petrópolis: Vozes, 2005.

VAILLANT, D.; MARCELO, C. M. Ensinando a ensinar: as quatro etapas de uma aprendizagem. Curitiba: UTFPR, 2012.

VEENMAN, S. Perceived problems of beginning teachers. Review of Educactional Research, v. 54, n. 2, p. 143-178, 1984. Disponível em: https://journals.sagepub.com/doi/10.3102/00346543054002143. Acesso em: 05 ago. 2020.

Ev'Ângela Batista Rodrigues de Barros: Professora Adjunta IV da Pontifícia Universidade Católica de Minas Gerais, membro do corpo docente do Programa de PósGraduação em Letras. Mestre (1992) e doutora em Estudos Linguísticos (2006) pela UFMG. Graduada em Letras (UFMG) e Pedagogia (IEMG). Membro dos grupos de pesquisa ELinc e NELLF. Coordenadora da área de Letras do Pibid (2011-2013), de Gestão de Processos (2013-2018) e Coordenadora Institucional do Pibid PUC Minas (2018-2020). Editora Gerente de Conecte-se! Revista Interdisciplinar de Extensão e da Revista do $\mathrm{ICH}$.

Orcid: https://orcid.org/0000-0001-8094-2329

E-mail: evangelabrbarros.2@gmail.com

Lorene dos Santos: Professora Adjunta IV da Pontifícia Universidade Católica de Minas Gerais (membro do corpo docente do Programa de Pós-Graduação em Educação); Professora da Faculdade de Educação da Universidade do Estado de Minas Gerais (UEMG). Mestre (1997) e Doutora (2010) em Educação pela FaE/UFMG, Graduada em História (UFMG) e em Comunicação Social - Jornalismo (PUC Minas). Líder do Grupo de Estudos e Pesquisas sobre Profissão Docente - 
GEPPDOC/CNPq; Coordenadora Institucional (2010-2012) e da Área de História (2012-2018) do PIBID PUC Minas.

Orcid https://orcid.org/0000-0002-7629-1954

E-mail: lorenedossantos@smail.com

Este periódico utiliza a licença Creative Commons Attribution 3.0, para periódicos de acesso aberto (Open Archives Iniciative - OAI). 